\title{
Genetic Determinants of Endometriosis and Uterine Myoma Combinatin

\author{
${ }^{1}$ Irina V. Ponomarenko, ${ }^{2}$ Vladimir F. Kulikovskiy, ${ }^{3}$ Irina V. Batlutkaya, ${ }^{4}$ Alexey V. Polonikov, \\ ${ }^{5}$ Mikhail I. Churnosov \\ 1, 2,3, 5 Belgorod State University, ${ }^{4}$ Kursk State Medical University, 308015, Belgorod, Pobeda Street, 85, \\ Russia \\ Email:Ponomarenko_i@bsu.edu.ru.
}

\section{Received: 15th December 2017, Accepted: 20th December 2017, Published: 31st December 2017}

\begin{abstract}
Benign proliferative diseases of the uterus, which include uterine myoma and endometriosis occupy a leading place in the structure of gynecological diseases. The objective of the research was a bioinformatic study of the involvement of candidate genes in the formation of a combination of endometriosis with uterine myoma in women. As a result of the study, 5 molecular-genetic markers were genotyped in 109 patients with a combination of endometriosis with uterine myoma and 981 women of the control group. It has been established that the combinations of molecular genetic markers rs466639 with rs713586 and rs10441737 (OR = $2.45)$ and rs466639 with rs3756261, rs713586 and rs10980926 $(\mathrm{OR}=1.36)$ are risk factors for the development of a combination of endometriosis and uterine myoma among women of the Central region of Russia.
\end{abstract}

Keywords: Endometriosis, Uterine Myoma, Combined Pathology, Genetic Polymorphism

\section{Introduction}

The relevance of benign proliferative diseases of the uterus, which include uterine myoma and endometriosis, is associated with a fairly high prevalence and comorbidity of these pathological conditions due to the common etiology and pathogenesis, which explains a similar in most cases clinical pattern.

Endometriosis is a process when benign proliferation of tissue occurs outside the uterine cavity, similar to the endometrium in the morphological and functional properties [Bruner-Tran K.L. et al., 2013]. This disease occurs in $10 \%$ of women of reproductive age [Rahmioglu N. et al., 2015] and is one of the main causes of infertility, dysmenorrhea, dyspareunia, as well as chronic pelvic pain, adhesion of the pelvic organs, which together leads to a general deterioration quality of life of women [Truskinovsky A.M. et al., 2014; Ponomarenko I.V. et al., 2016].

Uterine myoma is one of the most common female genital benign tumors that occurs in $20-40 \%$ of women of reproductive age [Churnosov M.I. et al., 2014; Taylor D.K. et al., 2015; Pachomov S.P. et al., 2016]. Clinical manifestations of this disease are associated with uterine bleeding, pain, compression of adjacent organs, miscarriage [Commandeur A.E. et al., 2015; Krivoshei I.V. et al., 2015a]. As a consequence, uterine myoma becomes the main cause of hysterectomy in many countries of the world.

Benign proliferative diseases of the uterus have a common pathogenesis and therefore often occur concomitantly. Thus, $27 \%$ of women with endometriosis have concomitant uterine myoma [Donato N.D. et al., 2014; Krivoshei I.V. et al., 2015 b].

One of the factors predetermining the development of endometriosis and uterine myoma may be the age of menarche and associated candidate genes [Elks C.E. et al., 2010].

The objective of the study was a bioinformatic study of the involvement of candidate genes in the formation of a combination of endometriosis with uterine myoma in women.

\section{Materials and Methods}

In this study, patients with a combination of endometriosis and uterine myoma $(n=109)$ were selected from a group of 947 patients with various uterine hyperplastic processes. The sample was made on the basis of the gynecological department of the perinatal center of St. Joasaph Belgorod Regional Clinical Hospital. Patients with a combination of uterine myoma and endometriosis underwent a clinical, clinical and laboratory examination, ultrasound examination of pelvic organs, hysteroscopy followed by targeted diagnostic scraping of the uterine cavity and histological examination of scrapings. All patients signed an informed consent for inclusion in the study and use of the data obtained. The control group involved 981 women without proliferative diseases of the pelvic organs.

All patients with endometriosis and uterine myoma were performed typing of 5 molecular-genetic markers rs466639 RXRG, rs713586 DNAJC27, rs10441737 ZNF483, rs10980926 ZNF483, rs3756261 EGF. The choice of these polymorphic markers for the study is due to their significant regulatory and expression potential (HaploReg (v.4.1.) (http://compbio.mit.edu/HaploReg)) and the important ethiopathogenetic significance of these 
genes for hyperplastic uterine disease [Commandeur A.E. et al., 2015].

As the material for the study we used $8-9 \mathrm{ml}$ of venous blood taken from the cubital vein of a proband. A genomic DNA was isolated from peripheral blood by the method of phenolchloroform extraction [Miller S.A., 1988]. Analysis of the investigated loci was carried out by the method of polymerase chain reaction of DNA synthesis with the use of oligonucleotide primers and probes.

Statistical processing of data was carried out using "STATISTICA forWindows 6.0" and "MicrosoftExcel 2007" software packages. To analyze the compliance of the observed distribution of genotypes with the expected one, based on HardyWeinberg equilibrium, we used $\chi^{2}$ test.

A bioinformatic study was performed by APSampler [http://sources.redhat.com/cygwin/], operating
Markov chain Monte Carlo, and Bayesian nonparametric statistics [Favorov A.V. et al., 2005]. Results and Discussion

We examined 109 women with endometriosis and uterine myoma and 981 women of the control group. The main characteristics of the study and control groups are shown in Table 1. The control group is fully comparable with the sample of patients with a combination of endometriosis and uterine myoma by age, nationality and place of birth.

An analysis of the distribution of studied polymorphic markers of candidate genes showed that for all the studied loci in the group of patients with uterine myoma and hyperplastic endometrium processes, as well as in the control sample, the empirical distribution of genotypes corresponds to the theoretically expected one at Hardy-Weinberg equilibrium $(\mathrm{p}>0.05)$.

Table 1. Characteristics of the Subjects from the Case and Control Groups

\begin{tabular}{|c|c|c|}
\hline Characteristics & Cases & Controls \\
\hline Total & 109 & 981 \\
\hline Age, $\mathrm{yrs}$ & $42.44 \pm 7.81$ & $39.94 \pm 9.31$ \\
\hline Height, $\mathrm{cm}$ & $1.66 \pm 0.07$ & $1.65 \pm 0.06$ \\
\hline Weight, $\mathrm{kg}$ & $75.11 \pm 13.41$ & $69.69 \pm 12.49$ \\
\hline IMB & $27.39 \pm 5.03$ & $25.69 \pm 4.24$ \\
\hline
\end{tabular}

A high risk of a combination of endometriosis with uterine myomas $(\mathrm{OR}=2.39)$ in women is also determined by the combination of four genetic markers C rs466639 with A rs3756261 with T rs713586 with $\mathrm{G}$ rs10980926. The concentration of this combination among patients with endometriosis and uterine myoma $(85.85 \%)$ is 1.20 times higher than that of the control group $(71.77 \%, \mathrm{p}=0.0008$, $\mathrm{p}_{\text {perm }}=0.0012,95 \%$ CI 1.36-4.19).

The online service HaploReg (v.4.1.) (http://compbio.mit.edu/HaploReg) was used to study the regulatory potential and the effect on gene expression of significant polymorphisms associated with endometriosis and uterine myoma. The genetic polymorphism rs466639, localized in the intron portion of the $R X R G$ gene, is in the region of the enhancer of 10 types of tissues (including skeletal muscles in women, smooth muscles of a number of internal organs, adipose tissue, etc.). Moreover, the alternative allele $\mathrm{C}$ of this polymorphism significantly increases the affinity of the regulatory DNA motifs Foxa_disc3 (PWM=-12.0), GR_disc5 $(\mathrm{PWM}=+12.0), \mathrm{YY} 1 \_$known4 $(\mathrm{PWM}=+9.2)$. There are literature data (the results of GWAS studies) about the involvement of this locus in the formation of menarche age $(p=1 E-13$ and $p=2 E-24)$ [Elks C.E. et al., 2010; Perry J.R., 2014].

The genetic polymorphism rs713586, which is 8.5 $\mathrm{kb}$ from the 3rd end of the DNAJC27 gene, has a high regulatory and expressive potential. The "risk" $\mathrm{T}$ allele of this locus increases the affinity of the three DNA motifs - Pbx3_disc3 (PWM=+0.5), SP2_disc2 (PWM=+5.2), TATA_disc1 $(\mathrm{PWM}=+11.9)$ to regulatory influences. This polymorphic locus is associated with the expression level of the DNAJC27 genes ( $\mathrm{p}=5.08 \mathrm{E}-11), A D C Y 3$ $(\mathrm{p}=1.61 \mathrm{E}-35), \mathrm{RP} 11-44 \mathrm{~B} 20.1(\mathrm{p}=7.17 \mathrm{E}-22)$ in blood cells, and the $P O M C$ gene in muscle tissue $(\mathrm{p}=1.4 \mathrm{E}-$ $05)$. According to the results of GWAS studies, the genetic polymorphism rs713586 is associated with the body mass index ( $\mathrm{p}=6 \mathrm{E}-22)$ [Speliotes E.K. et al., 2011].

The polymorphic locus rs10441737 of the ZNF483 gene (intron region) is associated with the expression level of the ZNF483 gene in adipose tissue $(p=1.94 \mathrm{E}-9)$ and has a significant regulatory potential as it makes part of 9 DNA motifs. It should be noted that the allele $\mathrm{C}$ of this locus increases the affinity of the Hox10 motifs (PWM=+2.0), Hoxb8 $(\mathrm{PWM}=+2.9)$, Mef2_known4 (PWM=+11.1), Nux62 (PWM=+0.6), while the alternative $\mathrm{T}$ allele is associated with high affinity of Fox motifs (PWM=10.6), Pou1+1_1 (PWM=-11.7), Pou2f2_known4 $(\mathrm{PWM}=-5.4)$, Pou13+3 (PWM=-6.5), and Pou5 +1 - disc1 (PWM=-7.7). This polymorphism is also associated with the age of menarche $(p=4 E-15)$ [Demerath E.W. et al., 2013].

Another significant polymorphic locus of the gene ZNF483 - rs10980926 is also associated with the level of expression of the gene ZNF483 in adipose tissue $(\mathrm{p}=1.12 \mathrm{E}-0.6)$, KIAA0368 in the blood $(\mathrm{p}=1.75 \mathrm{E}-9)$ and is localized in 9 regulatory DNA 
motifs. A allele is associated with increased affinity for the regulatory influences of the following motifs: Irf_known4 (PWM=+11.9), Nkx2_7 (PWM=-12.0), Nkx2_9 (PWM=+11.9), RXRA - disc3 $(\mathrm{PWM}=+1.7)$. While the $\mathrm{G}$ allele alternative to it is connected with the increased affinity of motives AD1_known4 (PWM=-2.7), AFF3_disc1 (PWM=-7.7), BHLHE40_disc1 (PWM=-7.5), GATA_disc6 (PWM=-11.7), Mxi1_known1 (PWM=-3.5), 2EB1_known4 (PWM=-11.9), ZEB1_known5 $(\mathrm{PWM}=-12.0)$. This genetic polymorphism is involved in the formation of menarche age $(p=4 \mathrm{E}-$ 11) [Elks C.E. et al., 2010] and is associated with anthropometric characteristics at pubertal age ( $p=2 E-7)$ [CousminerD.L. et al., 2014].

The genetic polymorphism rs 3756261 , located in the region of $1.7 \mathrm{~kb}$ from the 5th end of the gene $E G F$, marks the regulatory DNA motif Obox3. With the increased affinity of this motive, the A allele $(\mathrm{PWM}=+2.5)$ is associated with regulatory influences. $E G F$ plays a key role in such processes as proliferation, differentiation of different cell types, oncogenesis [Yarom N. et al., 2011; Lien G.S. et al., 2014]. It should be noted that overexpression of $E G F$ correlates with an increase in the likelihood of metastatic development [Chang W.C. et al., 2015].

\section{Summary}

Thus, the results of the study allow us to conclude that the combinations of molecular genetic markers rs466639 with rs713586 and rs10441737 (OR = $2.45)$ and rs466639 with rs3756261, rs713586 and rs 10980926 (OR = 1.36) are risk factors for the development of a combination of endometriosis and uterine myoma among women of the Central region of Russia.

\section{References}

1. Bruner-Tran, K.L., J.L. Herington, A.J. Duleba, H.S. Taylor, K.G. Osteen, 2013. Medical Management of Endometriosis: Emerging Evidence Linking Inflammation to Disease Pathophysiology. Minerva Ginecol., 65(2):199-213.

2. Chang, W.-C., S.-L. Wu,. W.-C. Huang, 2015. PTX3 gene activation in EGFinduced head and neck cancer cell metastasis. Oncotarget, 6(10): 7741-7757.

3. Churnosov, M.I., O.B. Altuchova, N.A. Demakova, I.V.Krivoshei, V.I. Evdokimov, I.V. Batlutskaya, A.V. Polonikov, 2014. Associations of Cytokines Genetic Variants with Myomatous Knots Sizes. Research Journal of Pharmaceutical, Biological and Chemical, 5(6): 1344-1347.

4. Commandeur, A.E., A.K. Styer, J.M. Teixeira, 2015. Epidemiological and genetic clues for molecular mechanisms involved in uterine leiomyoma development and growth. Hum Reprod Update, 21(5): 593-615.

5. Cousminer, D.L., E. Stergiakouli, D.J. Berry, 2014. Genome-wide association study of sexual maturation in males and females highlights a role for body mass and menarche loci in male puberty. Human Molecular Genetics, 23(16): 4452-4464.

6. Demerath, E.W., C.-T. Liu, N. Franceschini, G. Chen, J.R. Palmer,E.N. Smith, C.T.L. Chen, C.B. Ambrosone, 2013. Genome-wide association study of age at menarche in African-American women. Hum Mol Genet, 22(16): 33293346.

7. Donato, N.D., R. Seracchioli, 2014. How to Evaluate Adenomyosis in Patients Affected by Endometriosis? Available at: http://www.ncbi.nlm.nih.gov/pmc/articles/ PMC4146361/(accessed 12.08.2014).

8. Elks, C.E., J.R.B. Perry, P. Sulem, D.I. Chasman, N. Franceschini, C. He, K.L. Lunetta, 2010. Thirty new loci for age at menarche identified by a meta-analysis of genome-wide association studies. Nat Genet, 42(12): 1077-1085.

9. Favorov, A.V., T.V. Andreewski, M.A. Sudomoina, O.O. Favorova. AFormattoExchangeGene-

RelatedProbabilities.

BiomolecularStructure\& Dynamics, 29(2): 417-423.

10. Krivoshei, I.V., O.B. Altuchova, O.V. Golovchenko, V.S. Orlova, A.V. Polonikov, M.I. Churnosov, 2015 a. Genetic factors of hysteromyoma. Research Journal of Medical Sciences, 9 (4): 182-185.

11. Krivoshei, I.V., O.B. Altuchova, A.V. Polonikov, M.I. Churnosov, 2015 b. Bioinformatic Analysis of the Liability to the Hyperplastic Processes of the Uterus. Research Journal of Pharmaceutical, Biological and Chemical Sciences, №6(5): 1563-1566.

12. Lien, G.-S., M.-S. Wu, M.-Y. Bien, 2014. Epidermal Growth Factor Stimulates Nuclear Factor- $\kappa \mathrm{B}$ Activation and Heme Oxygenase-1 Expression via c-Src, NADPH Oxidase, PI3K, and Akt in Human Colon Cancer Cells. PLoS One, 9(8): e104891.

13. Miller, S. A., Dykes, D. D., Polesky, H. F., 1988. A simple salting out procedure for extracting DNA from human nucleated cells. Nucleic acids research, 16(3): 1215.

14. Pachomov, S.P., I.V. Ponomarenko, V.F. Kulikovskiy, V.S. Orlova, E.N. Krikun, I.N. Sorokina, I.V. Batlutskaya, O.Y. Bushueva, 2016. Analysis of Candidate Genes for 
Uterine Fibroids. Research Journal of Pharmaceutical, Biological and Chemical Sciences, №7(6): 3239-3242.

15. Perry, J.R., 2014. Parent-of-origin specific allelic associations among 106 genomic loci for age at menarche. Nature. 2014; 514(7520):92-97.

16. Ponomarenko, I.V., Altuchova, O.B., Golovchenko, O.V., Sorokina, I.N., Polonikov, A.V., Bushueva, O.Y., and Churnosov, M.I., 2016. Molecular-genetic factors of genital endometriosis. International Journal of Pharmacy and Technology, 8(2): 14190-14195.

17. Rahmioglu, N., S. Macgregor, A.W. Drong, Å.K. Hedman, H.R. Harris, J.C. Randall, I. Prokopenko, 2015. Genome-wide enrichment analysis between endometriosis and obesity-related traits reveals novel susceptibility loci. Hum Mol Genet,24(4): 1185-1199.

18. Speliotes, E.K., L.M. Yerges-Armstrong, J. $\mathrm{Wu}$, 2011. Genome-Wide Association Analysis Identifies Variants Associated with Nonalcoholic Fatty Liver Disease That Have Distinct Effects on Metabolic Traits. PLoS Genet., 7(3):e1001324.

19. Taylor, D.K., K. Holthouser, J.H. Segars, 2015. Recent scientific advances in leiomyoma (uterine fibroids) research facilitates better understanding and management. List., 4: 183.

20. Truskinovsky, A.M., B. Lifschitz-Mercer, B. Czernobilsky, 2014. Hyperplasia and carcinoma in secretory endometrium: a diagnostic challenge. Gynecological Pathology, 33(2): 107-113.

21. Yarom, N., D.J. Jonker, 2011. The role of the epidermal growth factor receptor in the mechanism and treatment of colorectal cancer. Discov Med., 11(57): 95-105. 